\title{
A simulation study investigating the spread of water droplets during oxygen therapy: where is it safe to stand?
}

\author{
Jeevakan Subramaniam, MBBS (D) Daveena Meeks, MBBS • Anna Forbes, BMBCh, FRCA • \\ Danny J. N. Wong, PhD, FRCA $\cdot$ Christopher Ward, MBChB, FRCA $\cdot$ Andrew McKechnie, MBBS, FCAI
}

Received: 19 March 2021/Revised: 29 March 2021 / Accepted: 30 March 2021 / Published online: 27 April 2021

(C) Crown 2021

To the Editor,

The COVID-19 pandemic is an international public health emergency. COVID-19 primarily causes respiratory failure, with many patients requiring respiratory support. ${ }^{1-3}$ The spread of SARS-CoV-2 particles via aerosol $(<5 \mu \mathrm{m})$ has received a great deal of attention. ${ }^{4,5}$ Nevertheless, water droplets $(>5 \mu \mathrm{m})$ remain an important vector. ${ }^{4}$

There is a risk of SARS-CoV-2 infection spread to staff from respiratory droplets and aerosols generated during medical procedures, including endotracheal intubation, non-invasive ventilation, and high-flow nasal oxygen (HFNO). Despite this, we are not aware of any research that has simulated the spread of water droplets $(>5 \mu \mathrm{m})$ during oxygen therapy. Such research may determine where, during aerosol-generating medical procedures, it is safer to stand, and where the risks are higher.

We performed a mannequin simulation assessing the spread of larger water droplets during preoxygenation in the operating room of a district general hospital in London, UK.

An airway mannequin (SimMan®; Laerdal Medical AS, Stavanger, Norway) was positioned on an elevation pillow and modified, introducing an atomizer in the mouth and replacing the lungs with a breathing circuit and ventilator (Dräger Primus ${ }^{\circledR}$; Drägerwerk AG \& Co. KGaA, Lübeck, Germany; Figure 1). The ventilator was set to a tidal

J. Subramaniam, MBBS $(\varangle) \cdot$ D. Meeks, MBBS .

A. Forbes, BMBCh, FRCA - C. Ward, MBChB, FRCA .

A. McKechnie, MBBS, FCAI

Lewisham and Greenwich NHS Trust, London, UK

e-mail: jeevakan@live.com

D. J. N. Wong, PhD, FRCA

Guy's and St Thomas' NHS Trust, London, UK volume of $500 \mathrm{~mL}, 12$ times per minute; $0.5 \mathrm{~mL}$ of ultraviolet (UV)-luminescent fluid (RLD3; Ring, Leeds, United Kingdom) was injected through the atomizer with each breath.

The spread of fluid was visualized using a UV light and its furthest distance from the mouth was measured in three dimensions: longitudinally along the length of the bed, lateral to the mouth, and vertically above the mouth.

Three scenarios were performed for three minutes each and repeated five times. Normal ventilation without oxygen was assessed as a control and then preoxygenation was assessed using two common methods: a size 4 face mask connected to a Mapleson C circuit (Intersurgical Ltd, Wokingham, UK) and HFNO (delivered using Optiflow ${ }^{\mathrm{TM}}$; Fisher and Paykel Healthcare, Auckland, New Zealand).

Pairwise statistical comparisons between groups was made using the Mann-Whitney $\mathrm{U}$ test, with a significance level set at $P<0.05$.

Simulation of normal ventilation without supplemental oxygen (control) resulted in a spread of droplets to a mean (standard deviation [SD]) nearest distance of 85 (1) $\mathrm{cm}$ longitudinally, 40 (1) cm laterally, and $50(0) \mathrm{cm}$ vertically.

Preoxygenation using a face mask and Mapleson C circuit did not spread droplets beyond the face mask. This was significantly less than the other methods in all three dimensions.

Preoxygenation with HFNO resulted in a spread of droplets to a mean (SD) of 71 (1) cm longitudinally, 64 (1) $\mathrm{cm}$ laterally, and $55(0) \mathrm{cm}$ vertically. This was significantly longer laterally and vertically, but not longitudinally. Measurements for longitudinal spread were all taken caudally as there was no spread beyond the head of the mannequin using any method.

These findings indicate that droplets do not spread beyond the mask during simulated face mask oxygenation. 
FIGURE 1 A photo illustrating the experiment setup.

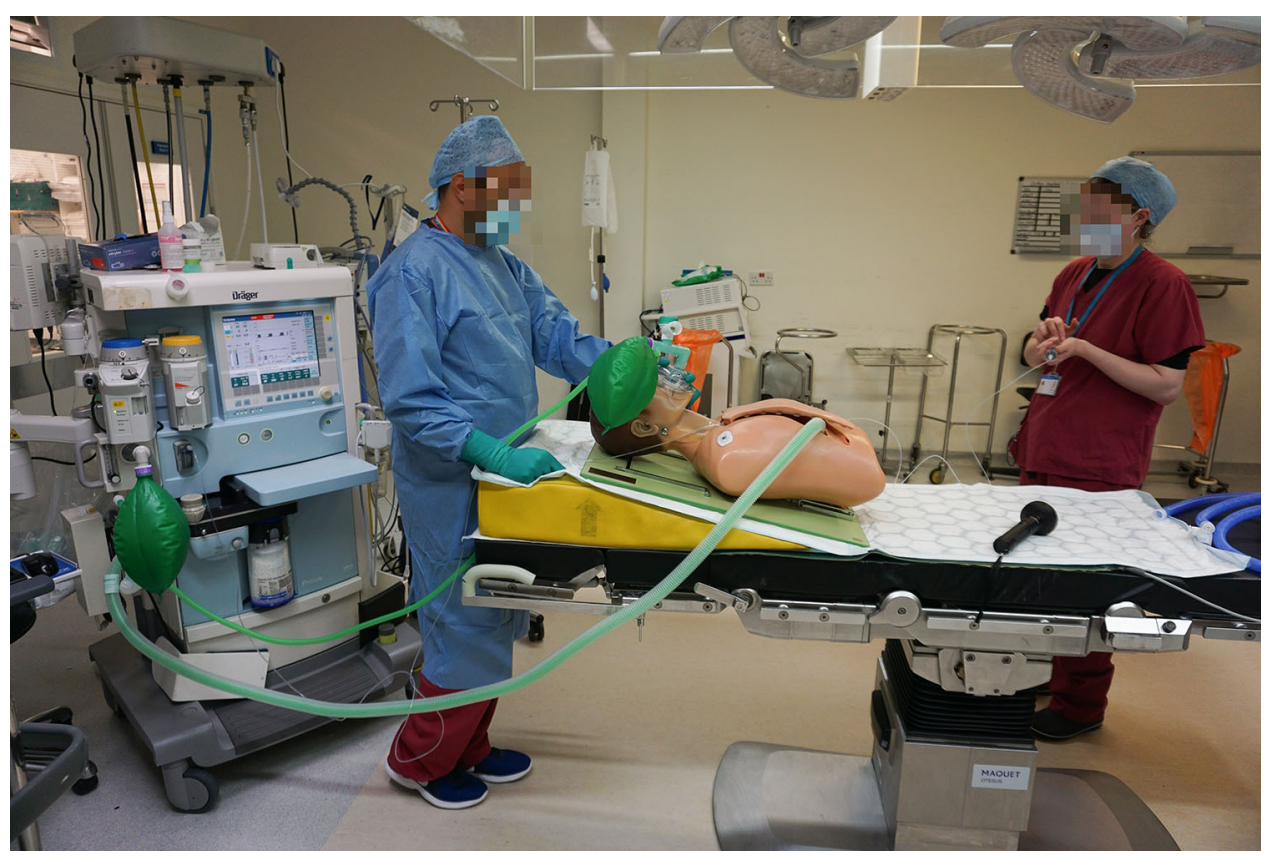

There was a significant difference in the mean droplet spread between HFNO and simulated normal ventilation. Notably, no spread was found above the head during any method.

The study of droplet spread during oxygen therapy has the potential to improve staff safety during intubation, and aiding staff in "lower risk" areas not recommending the use of "full" personal protective equipment (PPE). Although our results are limited by a small sample size, using a non-human experimental model, and using a surrogate marker for actual COVID-19 infection, preoxygenation using a face mask may represent the safest method, while HFNO may spread droplets more widely. These results may imply a "high risk zone" around patients, to be avoided by healthcare professionalspossibly minimizing exposure. The lack of spread above the head with any method suggests that this may be the safest zone, of particular importance to staff caring for higher risk or confirmed COVID-19 patients, such as nurses in environments where full PPE is not used. Nevertheless, because our results are hypothesisgenerating, it would be inappropriate to use this data to inform changes in actual clinical care.

Disclosures None.

Funding statement None.
Editorial responsibility This submission was handled by Dr. Philip M. Jones, Deputy Editor-in-Chief, Canadian Journal of Anesthesial Journal canadien d'anesthésie.

\section{References}

1. Guan WJ, Ni ZY, Hu Y, et al. Clinical characteristics of coronavirus disease 2019 in China. N Engl J Med 2020; 382: 1708-20.

2. Zhou F, Yu T, Du R, et al. Clinical course and risk factors for mortality of adult inpatients with COVID-19 in Wuhan, China: a retrospective cohort study. Lancet 2020; 395: 1054-62.

3. Grasselli G, Zangrillo A, Zanella A, et al. Baseline characteristics and outcomes of 1591 patients infected with SARS-CoV-2 admitted to ICUs of the Lombardy region, Italy. JAMA 2020; 323: $1574-81$.

4. World Health Organization. Transmission of SARS-CoV-2: implications for infection prevention precautions. Available from URL: $\quad$ https://www.who.int/publications-detail/modes-oftransmission-of-virus-causing-covid-19-implications-for-ipcprecaution-recommendations (accessed March 2021).

5. Wilson NM, Norton A, Young FP, Collins DW. Airborne transmission of severe acute respiratory syndrome coronavirus-2 to healthcare workers: a narrative review. Anaesthesia 2020; 75: 1086-95.

Publisher's Note Springer Nature remains neutral with regard to jurisdictional claims in published maps and institutional affiliations. 